\title{
A sustainable biorefinery to convert agricultural residues into value-added chemicals
}

\author{
Zhiguo Liu, Wei Liao and Yan Liu*
}

\begin{abstract}
Background: Animal wastes are of particular environmental concern due to greenhouse gases emissions, odor problem, and potential water contamination. Anaerobic digestion (AD) is an effective and widely used technology to treat them for bioenergy production. However, the sustainability of AD is compromised by two by-products of the nutrient-rich liquid digestate and the fiber-rich solid digestate. To overcome these limitations, this paper demonstrates a biorefinery concept to fully utilize animal wastes and create a new value-added route for animal waste management.

Results: The studied biorefinery includes an AD, electrocoagulation (EC) treatment of the liquid digestate, and fungal conversion of the solid fiber into a fine chemical — chitin. Animal wastes were first treated by an AD to produce methane gas for energy generation to power the entire biorefinery. The resulting liquid digestate was treated by EC to reclaim water. Enzymatic hydrolysis and fungal fermentation were then applied on the cellulose-rich solid digestate to produce chitin. EC water was used as the processing water for the fungal fermentation. The results indicate that the studied biorefinery converts $1 \mathrm{~kg}$ dry animal wastes into $17 \mathrm{~g}$ fungal biomass containing $12 \%$ of chitin (10\% of glucosamine), and generates $1.7 \mathrm{MJ}$ renewable energy and $8.5 \mathrm{~kg}$ irrigation water.

Conclusions: This study demonstrates an energy positive and freshwater-free biorefinery to simultaneously treat animal wastes and produce a fine chemical — chitin. The sustainable biorefinery concept provides a win-win solution for agricultural waste management and value-added chemical production.
\end{abstract}

Keywords: Anaerobic digestion, Animal wastes, Biorefinery, Chitin/chitosan, Electrocoagulation, Fungal fermentation

\section{Background}

There are 450,000 animal feeding operations (AFOs) in the U.S., which produces approximately 1.3 billion wet tons (335 million dry tons) of animal wastes per year [1, 2]. Animal wastes are of particular environmental concern due to greenhouse gases emission, odor problem, and potential surface and ground water contamination. A recent trend in animal waste management is the renewed interest in using anaerobic digestion (AD) technology for energy production and carbon sequestration [3, 4]. Even though $\mathrm{AD}$ is an effective method for producing methane energy and reducing volatile organics, it is incompetent to sequester all carbons and remove nutrients in animal

*Correspondence: liuyan6@msu.edu

Department of Biosystems and Agricultural Engineering, Michigan State

University, 524 S. Shaw Ln. Room 203, East Lansing, Ml 48824-1323, USA wastes. After digestion, solid digestate still has a high carbon content [5, 6], and liquid digestate contains significant amounts of nitrogen, phosphorus, and total solids $[7,8]$.

Many studies have been carried out to treat liquid digestate such as active carbon adsorption [9], chemical coagulation and flocculation [10], UV treatment [11] and ozone treatment [12]. Regardless good treatment performance of these methods, high-energy input and additional chemical usage make them less attractive to be commercially implemented. Meanwhile, electrocoagulation (EC) has recently been studied to treat high-strength wastewater (high solids and chemical oxygen demand) [13]. Due to its high removal efficiency and chemicalfree nature, EC technology has a short retention time and avoids a secondary pollution [14]. Our previous studies 
have successfully established an EC treatment process that is capable of simultaneously treating AD liquid effluent and cleaning up raw biogas, and developed a tandem membrane filtration process to purify the EC treated water [15]. The relatively clean EC treated water can then be used as the processing water for cellulosic biorefinery.

As for solid digestate, treatments such as composting and incineration have been widely used [16, 17]. Besides these traditional methods, Sun et al. applied pyrolysis to convert solid digestate into biochar as adsorbent material [18]. Biological conversion processes have also been developed to use solid digestate as a viable cellulosic feedstock for bioethanol and biodiesel production [19, 20]. These studies indicate that solid digestate has much better commercial uses as a cellulosic biorefining feedstock rather than a soil amendment or a combustion fuel.

However, investigations on fully utilizing AD effluent (both solid digestate and liquid digestate) for value-added chemical production have not been reported to date. New technologies are urgently needed to realize such utilization, so that environmentally sound and economically feasible animal waste management can be achieved.

Chitin is a natural amino polysaccharide widely distributed in the animal and plant kingdom. The structure of chitin is a linear polysaccharide made up of unbranched $\beta$-(1,4)-2-acetamido-2-deoxy-D-glucopyranosyl residues which is also called N-acetyl-D-glucosamine. The structural characteristics make chitin a very attractive biopolymer that can be used as coagulating agents in wastewater treatment, plant seed coating agents in agricultural industry, and biomaterials (e.g., absorbable sutures) in biomedical industry [21, 22]. Traditionally, chitin is extracted from crustacean insects and shell fishes. Compared to the chitin from shellfishes, fungal chitin has advantages of lower level of inorganic materials, no geographic or seasonal limitations [23, 24], and better effectiveness in inducing the plant immune response (as a fertilizer) [25].

Therefore, to convert animal wastes into a high-value chemical-chitin, this paper developed a sustainable biorefinery concept integrating $\mathrm{AD}, \mathrm{EC}$ and fungal fermentation (Fig. 1). Animal wastes were first treated by an $\mathrm{AD}$ to produce methane gas for energy generation to power the entire biorefinery. The resulting liquid digestate was treated by EC to reclaim water. Pretreatment, enzymatic hydrolysis and fungal fermentation were then applied on the cellulose-rich solid digestate using the EC reclaimed water as the processing water to produce chitin. The studied biorefinery not only converts animal wastes into high-value added products, but also eliminates freshwater use and external power supply, which represents a promising utilization path of agricultural waste management.

\section{Methods}

\section{Anaerobic digestion}

Anaerobic digestion of animal wastes was carried out on a commercial anaerobic digester located at a private dairy farm (3000 cows) in Michigan (42N 46'29.51", $\left.85 \mathrm{~W} 19^{\prime} 10.14^{\prime \prime}\right)$. The animal feeds of the dairy farm were alfalfa and corn silage, which are blended based on the Natural Research Council (NRC)'s standard total mixed rations (TMRs) for dairy cattle [26]. The farm uses corn straw as the bedding materials, and adopts a scrape system to collect animal feces. The digester is a completely stirred tank reactor (CSTR) operated at temperature of $40{ }^{\circ} \mathrm{C}$ and retention time of 22 days. The effective volume of the digester is $10,000 \mathrm{~m}^{3}$. The biogas is combusted by two $400 \mathrm{~kW}$ caterpillar $^{\circledR}$ generators to produce electricity. Two $5.5 \mathrm{~kW} \mathrm{FAN}^{\circledR}$ screw press separators with $2 \mathrm{~mm}$ screen are implemented to separate liquid and solid digestate of the $\mathrm{AD}$ effluent. The liquid and solid digestates were used to carry out the following EC treatment and fungal fermentation, respectively.

\section{EC treatment of liquid digestate}

EC was conducted in a column EC reactor described in a previous study [27] with minor modifications. Current level, retention time, and working volume were set as $10 \mathrm{~A}, 150 \mathrm{~min}$ and $3.5 \mathrm{~L}$, respectively, which were determined based on COD removal of the EC (Additional file 1: Figure S1). Total solid (TS) of the liquid digestate was $2.7 \%$. Voltage was monitored during the EC treatment. The EC effluent was collected and centrifuged at $230 \mathrm{~g}$ for $10 \mathrm{~min}$ to prepare EC water for the following experiments.

\section{Fungal fermentation of solid digestate \\ Pretreatment and enzymatic hydrolysis of solid digestate}

The EC water was used as the processing water to carry out pretreatment and enzymatic hydrolysis of solid digestate. Based on the optimization (Additional file 1: Tables $\mathrm{S} 1$ and S2), the preferred pretreatment condition of $2 \%$ of $\mathrm{NaOH}, 120{ }^{\circ} \mathrm{C}$ of reaction temperature, and $2 \mathrm{~h}$ of reaction time was selected with total solid loading fixed at $10 \%(\mathrm{w} / \mathrm{w})$. The $\mathrm{pH}$ of the treated slurry was adjusted to 5.5 using $30 \%$ sulfuric acid. C-TEC3 enzyme cocktail with H-TEC (sponsored by Novozyme North America, Franklinton, NC) was then added into the slurry to release mono-sugars under the conditions of $63 \mathrm{~h}$ of reaction time, $50{ }^{\circ} \mathrm{C}$ of reaction temperature, and $150 \mathrm{rpm}$ of shaking speed. The enzyme cocktail was prepared as: $9.10 \mathrm{mg}$ cellulose (CTEC3, protein content of $218 \mathrm{mg} \mathrm{mL}^{-1}$ ) and $1.43 \mathrm{mg}$ xylanase (HTEC3, protein content of $171 \mathrm{mg} \mathrm{mL}^{-1}$ ) per gram dry solid digestate. The hydrolysate was centrifuged at $7025 \mathrm{~g}$ for $10 \mathrm{~min}$, and the supernatant was further detoxified by $\mathrm{Ca}(\mathrm{OH})_{2}$ 


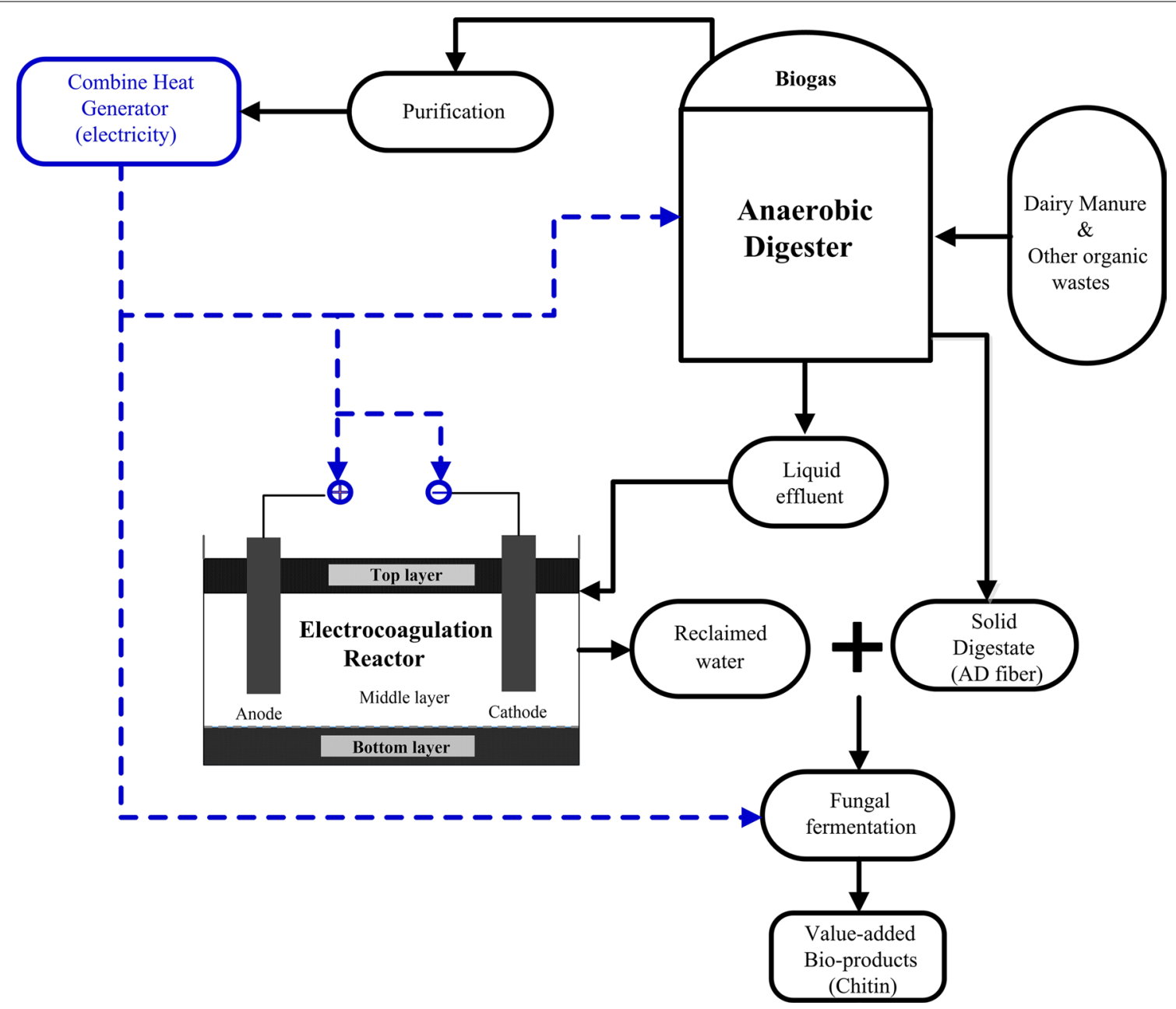

Fig. 1 Self-sustaining biorefinery concept. Black lines are for mass flow; blue lines are for energy flow

prior to the fermentation. The $\mathrm{pH}$ of the supernatant was adjusted to 10 with addition of $\mathrm{Ca}(\mathrm{OH})_{2}$ and the solution was maintained at $50{ }^{\circ} \mathrm{C}$ for $5 \mathrm{~h}$ with a shaking speed of $150 \mathrm{rpm}$. The $\mathrm{Ca}(\mathrm{OH})_{2}$ treated supernatant was centrifuged at $7025 \mathrm{~g}$ for $10 \mathrm{~min}$ again. The detoxified supernatant was collected. The $\mathrm{pH}$ was adjusted to 6.0 before the supernatant was stocked at $-20^{\circ} \mathrm{C}$ for further uses. All non-specified reagents were purchased from Sigma-Aldrich ${ }^{\circledR}$.

\section{Fungal strain and fermentation process}

Rhizopus oryzae ATCC 20344 (purchased from ATCC) was the strain used for chitin accumulation. Spores of $R$. oryzae ATCC 20344 were collected from the culture on the potato dextrose agar (PDA) medium (SigmaAldrich ${ }^{\circledR}$ ). The spore concentration of the collected spore solution was approximately $10^{7}$ spores $/ \mathrm{mL}$. $0.5 \mathrm{~mL}$ of the spore solution were inoculated to $100 \mathrm{~mL}$ of sterilized potato dextrose broth (PDB) medium (Sigma-Aldrich ${ }^{\circledR}$ ) with $8 \mathrm{~g} \mathrm{~L}^{-1}$ yeast extract (Acumedia ${ }^{\circledR}$ ), and cultivated at $30{ }^{\circ} \mathrm{C}, 180 \mathrm{rpm}$ for $36 \mathrm{~h}$ to prepare the seed. The detoxified solution from "Pretreatment and enzymatic hydrolysis of solid digestate" section was mixed with $3 \mathrm{~g} \mathrm{~L}^{-1}$ of $\mathrm{CaCO}_{3}$ and trace elements [28], and sterilized under $121{ }^{\circ} \mathrm{C}$ for $15 \mathrm{~min}$ to prepare the fermentation medium. $5 \mathrm{~mL}$ of the seed was inoculated to $45 \mathrm{~mL}$ of the fermentation medium. The fermentation was carried out at $30{ }^{\circ} \mathrm{C}$ and $180 \mathrm{rpm}$ for $120 \mathrm{~h}$. Samples were taken during the process to monitor kinetics of substrate consumption, growth, and product production.

\section{Analytical methods}

Chemical oxygen demand (COD), total phosphate (TP) and total nitrogen (TN) of animal wastes, liquid digestate, and EC treated water were measured using analytical kits purchased from $\mathrm{HACH}$ company [13]. TS, volatile solids (VS), cellulose, hemicellulose, and lignin of animal wastes and solid digestate were analyzed 
using the methods developed by National Renewable Energy Laboratory (NREL) [29]. Dissolved total organic carbon (TOC) of the liquid digestate was measured by a method previously reported [13]. A Shimadzu highperformance liquid chromatography (HPLC) equipped with Aminex 87H column, micro de-ashing guard column and a refractive index detector was used to analyze the sugars and organic acids. The HPLC method was adopted from a previous study [28]. Cellulose conversion was calculated as reported [5]. Xylan conversion was calculated as ((Volume of enzymatic hydrolysate) $(\mathrm{L}) *$ (Xylose concentration) $\left.\left(\mathrm{g} \mathrm{L}^{-1}\right)\right) /(($ Weight of solid digestate used for pretreatment) $(\mathrm{g}) *$ (Total solid content $)(\% \mathrm{w} / \mathrm{w}) *$ (Xylan content) $(\% \mathrm{w} / \mathrm{w}) * 1.136) * 100$. Chitin/chitosan were extracted from the collected fungal biomass [30, 31], and glucosamine content was also measured [32].

\section{Statistical analysis}

General linear model (GLM) analysis using the Statistical Analysis System program 9.3 (SAS Institute, Inc. Cary, NC) was conducted to select the preferred condition for pretreatment. Temperature, alkali loading, and reaction time were the parameters. Total sugar concentration (glucose + xylose) was the response. Analysis of variance (ANOVA) was used to interpret the data and draw conclusions.

\section{Results and discussion}

\section{Anaerobic digestion}

The characteristics of animal wastes (AD feedstock) were analyzed and summarized in Table 1 . High concentrations of COD, TN and TP in the animal wastes provide good nutritious sources to support growth of anaerobic microbes. 454 metric tons of the wet animal wastes are fed daily into the digester. Under 22 days of hydraulic retention time (HRT) and $40{ }^{\circ} \mathrm{C}$ of culture temperature, the AD generates $8495 \mathrm{~m}^{3}$ biogas per day with a methane content of $60 \%(\mathrm{v} / \mathrm{v})$, and produces 40 metric tons wet solid digestate and 397 metric tons liquid digestate per day. The energy demand to maintain the temperature of the $\mathrm{AD}$ and power accessory equipment is $5760 \mathrm{MJ} /$ day.

As aforementioned, $\mathrm{AD}$ is a natural and biological process good at confining organic wastes and producing renewable energy, though, it has limitations on completely degrading fiber and removing nutrients in agricultural wastes $[5,6]$. A large portion of cellulose, hemicellulose and lignin remained in the solid digestate (Table 2), and nutrients ( $\mathrm{P}$ and $\mathrm{N}$ ) in inorganic form exist in both liquid and solid digestates (Table 3 ). To improve the efficiency of animal waste utilization, it is in great need of new approaches to convert these remaining
Table 1 Characteristics of animal wastes and performance of the commercial CSTR digester

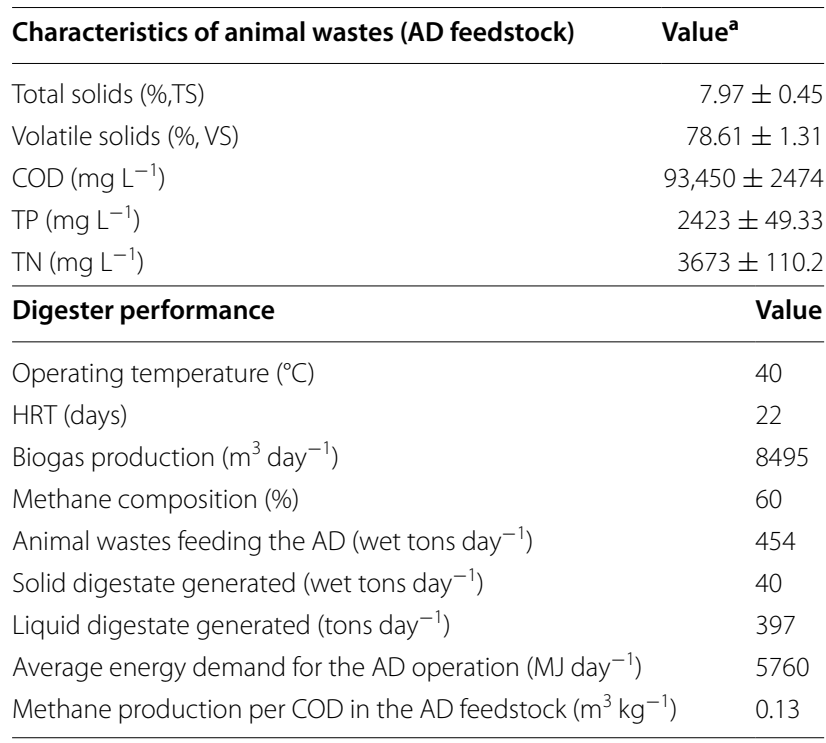

a Data are average of three replicates with standard deviation

Table 2 Characteristics of solid digestate and hydrolysate as well as cellulose and xylan conversion during the pretreatment and enzymatic hydrolysis

\begin{tabular}{lc}
\hline Characteristics of solid digestate & Value $^{\mathbf{a}}$ \\
\hline Total solids (\% TS) & $26.27 \pm 1.11$ \\
Volatile solids (\% VS) & $87.70 \pm 0.44$ \\
Cellulose (\% TS) & $20.56 \pm 0.21$ \\
Xylan (\% TS) & $11.77 \pm 0.39$ \\
Lignin (\% TS) & $33.05 \pm 0.23$ \\
\hline Sugar and acid concentrations of hydrolysate & Value $^{\mathbf{a}}$ \\
\hline Glucose ( $\mathrm{L}^{-1}$ ) & $15.78 \pm 0.36$ \\
Xylose (g L & $11.49 \pm 0.15$ \\
Acetate (g L & \\
\hline Cellulose and xylan conversion & $2.23 \pm 0.10$ \\
\hline Cellulose conversion (\%) & Value $^{\mathbf{a}}$ \\
\hline Xylan conversion (\%) & $64.34 \pm 2.28$ \\
\hline a Data are average of three replicates with standard deviation & \\
b The concentrations were for the hydrolysate after pretreatment, enzymatic \\
hydrolysis and detoxification
\end{tabular}

compounds into value-added chemicals. EC and fungal fermentation were adopted by this study to produce chitin from the digestates.

\section{Electrocoagulation of the liquid digestate}

It has been tested that the liquid digestate with a high COD concentration is not amendable for fungal 
Table 3 Characteristics of liquid digestate and EC water and performance of EC treatment

\begin{tabular}{lll}
\hline & Characteristics & Value \\
\hline Liquid digestate $^{\mathrm{a}}$ & Total solids (\% TS) & $2.64 \pm 0.03$ \\
& $\mathrm{COD}\left(\mathrm{mg} \mathrm{L}^{-1}\right)$ & $9490 \pm 14.1$ \\
& $\mathrm{TP}\left(\mathrm{mg} \mathrm{L}^{-1}\right)$ & $120 \pm 0.0$ \\
& $\mathrm{TN}\left(\mathrm{mg} \mathrm{L}^{-1}\right)$ & $1495 \pm 43.84$ \\
& TOC $\left(\mathrm{mg} \mathrm{L}^{-1}\right)$ & $4284 \pm 326$ \\
& Total solids (\% TS) & $0.78 \pm 0.11$ \\
EC water $^{\mathrm{a}}$ & $\mathrm{COD}\left(\mathrm{mg} \mathrm{L}^{-1}\right)$ & $1706.2 \pm 19.4$ \\
& TP $\left(\mathrm{mg} \mathrm{L}^{-1}\right)$ & $9.25 \pm 0.35$ \\
& TN $\left(\mathrm{mg} \mathrm{L}^{-1}\right)$ & $997.5 \pm 31.82$ \\
Removal efficiency & TS removal (\%) & 70.5 \\
& COD removal (\%) & 82.0 \\
TP removal (\%) & 92.3 \\
TN removal (\%) & 33.3 \\
\hline
\end{tabular}

a Data are average of three replicates with standard deviation

fermentation of chitin accumulation (data not shown). The liquid digestate must be treated prior to use as the processing water for the fermentation. EC as a non-membrane technology has advantages of high TS and COD removal efficiencies and dual-function of biogas cleanup and water reclamation [13], so that EC was adopted to treat the liquid digestate in this study. Table 3 shows the characteristics of liquid digestate and EC water as well as the performance efficiency of the EC treatment. Removal of TS, COD, TP, and TN during the EC were $70.5,82,92.3$ and $33.3 \%$, respectively. Compared to the removal of TS, COD, and TP, EC has lower efficiency on TN removal. It has been reported that EC is highly efficient in removing solid-dependent nutrients-TS, TP and COD [14], while it is incompetent in removing highly soluble compounds from solution such as ammonium ion (the main form of nitrogen in the liquid digestate) [13, 27]. Nevertheless, high level of nitrogen is favorable for fungal biomass growth and chitin synthesis, while limits production of other nontarget metabolites such as lactic acid and fumaric acid [33-35]. Therefore, using EC water with high nitrogen content as the processing water could be beneficial for $R$. oryzae culture to limit lactic acid production and accumulate more chitin.

Energy consumption is the main concern for the EC process. Electricity used during the EC process was monitored. The voltage was kept stable at $16 \pm 4 \mathrm{~V}$ in the first $120 \mathrm{~min}$, and increased to $30 \mathrm{~V}$ in the last $30 \mathrm{~min}$ of the process when the EC water turned into a relatively clear solution. According to the electrocoagulation principle, colloidal condition formed by charged (mostly negatively) particles has to be primarily broken to trigger massive precipitation $[14,36]$. Such solid precipitation leads to increase of electronic resistance, and subsequently results in the rapid climbing of voltage. The total energy consumption of the EC was $446 \mathrm{~kJ} / \mathrm{L}$ liquid digestate.

\section{Fungal conversion of solid digestate into chitin using the EC water as the processing water Pretreatment and enzymatic hydrolysis of solid digestate using the EC water as the processing water}

The solid digestate has relatively high contents of cellulose $(21 \%$ TS) and xylan (12\% TS), which provides a good carbohydrate source. A three-step process of pretreatment, enzymatic hydrolysis and detoxification was applied on the solid digestate to convert cellulose and hemicellulose into mono-sugars for $R$. oryzae fermentation. The EC water was used as the processing water. The hydrolysate after the three-step process contained $16 \mathrm{~g} \mathrm{~L}^{-1}$ glucose, $11 \mathrm{~g} \mathrm{~L}^{-1}$ xylose, and $2 \mathrm{~g} \mathrm{~L}^{-1}$ acetate. The cellulose and xylan conversion were 64 and $78 \%$, respectively, which are well aligned with a previous study [5]. The results also demonstrate that the EC water had no negative impacts on pretreatment, enzymatic hydrolysis or detoxification of the solid digestate.

\section{Fungal fermentation on the hydrolysate to produce chitin}

Fungal fermentation was carried out using the hydrolysate as the medium. The kinetic data demonstrate that $R$. oryzae can utilize glucose and xylose in the hydrolysate to accumulate biomass and produce chitin (Fig. 2). However, the consumption of glucose and xylose was observed in a tandem pattern where xylose utilization was after near-complete consumption of glucose. In addition, glucose was consumed much faster than xylose, which verified that $R$. oryzae prefers glucose to xylose as a carbon source [37]. Acetate was not significantly consumed during the fermentation, indicating that acetate is not a carbon source for $R$. oryzae. It is also interesting to observe that there was minimum lactate accumulation

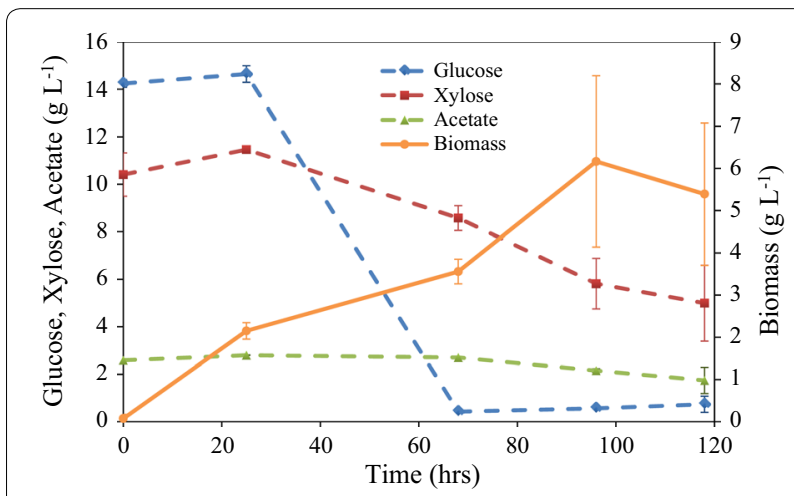

Fig. 2 Kinetics of fungal growth and substrate utilization. Data are average of three replicates with standard deviation 
during the fermentation on the hydrolysate. It has been reported that lactate metabolism of $R$. oryzae is significantly influenced by the nitrogen content in the medium [34]. High level of nitrogen tends to be more favorable for cell growth and chitin synthesis than lactate accumulation. The EC water as the processing water contains $998 \mathrm{mg} \mathrm{L}^{-1}$ of total nitrogen, which most likely influenced the fermentation for biomass accumulation and no lactate production. At the end of the exponential growth phase ( $96 \mathrm{~h}$ ), the biomass reached the maximum concentration of $6.17 \mathrm{~g} \mathrm{~L}^{-1}$. The corresponding biomass yield was $33 \%$ with respect to the amount of consumed glucose and xylose. However, even though xylose has been consumed by $R$. oryzae, there was still $5.81 \mathrm{~g} \mathrm{~L}^{-1}$ of xylose left in the broth at the end of the exponential growth phase. The xylose utilization efficiency was only $44 \%$. Improving xylose utilization of $R$. oryzae is critical to improve carbon utilization efficiency, and is currently under investigation.

Correspondingly, relationship between chitin/chitosan, glucosamine and biomass during the fermentation was also delineated (Fig. 3). Similar to the growth kinetics, chitin/chitosan and glucosamine all peaked at $96 \mathrm{~h}$, which is consistent with the reported observation that extractable chitin content maximized at the end of exponential phase [23]. The maximum concentrations of chitin/chitosan and glucosamine were 0.75 , and $0.50 \mathrm{~g} \mathrm{~L}^{-1}$, respectively. The yields of chitin/chitosan and glucosamine were 4.10 and $2.73 \%$ based on the amount of consumed glucose and xylose.

Several fungal strains such as Aspergillus niger, Mucor rouxii, and Candida albicans have been studied to produce chitin/chitosan on different feedstock (Table 4). Among them, $R$. oryzae is the one that demonstrates better performance on chitin accumulation. Higher chitin content and yield of $R$. oryzae were observed in previous studies (Table 5). However, most of them used pure sugar

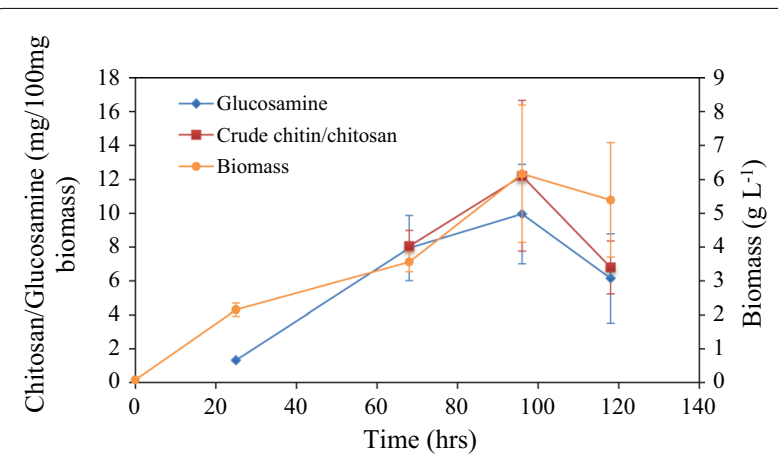

Fig. 3 Kinetics of chitin/chitosan and glucosamine accumulation. Data are average of three replicates with standard deviation or starch as the feedstock. There were only a few studies partially using agricultural residues as feedstock for chitin production [33, 34, 38]. This study is the first report that uses animal wastes as the sole carbon source to culture $R$. oryzae and accumulate chitin.

\section{Mass and energy balance analysis}

A mass and energy balance was conducted to evaluate the system performance (Fig. 4). The AD generated $162 \mathrm{~g}$ methane, $290 \mathrm{~g}$ solid digestate, and 11,234 g liquid digestate per kg dry animal wastes (Fig. 4). A portion of the liquid digestate (2063 g per $\mathrm{kg}$ dry animal wastes) mixed with $1323 \mathrm{~g}$ fermentation effluent per $\mathrm{kg}$ dry animal wastes was treated by EC to prepare the EC water for fermentation use. The EC sludge (1573 g per kg dry animal wastes) rich in phosphorus can be used as a fertilizer. The fungal fermentation on the hydrolysate of the solid digestate generated $17 \mathrm{~g}$ fungal biomass per kg dry animal wastes containing $12 \%$ of chitin and $10 \%$ of glucosamine. The water was completely self-sustained, and the freshwater was not needed. In addition, the EC water can cover the processing water for the fungal fermentation. A large demand of freshwater is one of the major challenges for fermentation processes of value-added chemical production [39-42]. Applying wastewater as processing water is becoming favorable to make the bioprocesses more sustainable $[43,44]$. The results in this study demonstrate that combining $\mathrm{AD}$ and $\mathrm{EC}$ can generate the processing water to satisfy the demand of the fungal fermentation for value-added chitin production. Besides the EC water used as the processing water, there was an extra amount of liquid digestate ( $9171 \mathrm{~g} / \mathrm{kg}$ dry animal wastes) rich in nitrogen and phosphorus, which can be used as a liquid fertilizer.

Energy balance also demonstrates that integrating AD with EC and fungal fermentation leads to an energy positive biorefining process (Table 5). AD as a powerhouse in the system generated $6.95 \mathrm{MJ}$ energy per $\mathrm{kg}$ animal wastes. EC and fungal fermentation (with pretreatment and hydrolysis) consumed 1.47 and $3.63 \mathrm{MJ}$ per kg animal wastes, respectively, to satisfy the demands of water treatment and fermentation process to convert $290 \mathrm{~g}$ of solid digestate into $17 \mathrm{~g}$ of chitin/chitosan. A positive net energy output of $1.69 \mathrm{MJ}$ per $\mathrm{kg}$ animal wastes was achieved by the studied biorefining concept.

\section{Conclusion}

The biorefinery system can produce $17 \mathrm{~g}$ fungal biomass with $12 \%$ chitin from $1 \mathrm{~kg}$ dry animal wastes. The mass and energy balance analysis concludes that the biorefinery is an energy neutral and freshwater-free biorefining system with a net energy and water outputs of $1.69 \mathrm{MJ} / \mathrm{kg}$ dry animal wastes and $8.5 \mathrm{~kg} / \mathrm{kg}$ dry 
Table 4 Partial fungal chitin/chitosan production summary

\begin{tabular}{|c|c|c|c|c|}
\hline Origin strain & Feedstock & Fermentation time (days) & Chitin/chitosan content & Reference \\
\hline Rhizopus oryzae ATCC 20344 & $100 \%$ AD fiber with treated AD effluent & 3 & 12.2 & This study \\
\hline Aspergillus niger & Yeast, peptone and dextrose broth & 15 & $11.1^{\mathrm{a}}$ & [23] \\
\hline Mucor rouxii & Yeast, peptone and dextrose broth & 21 & $20.13^{\mathrm{a}}$ & [23] \\
\hline Rhizopus oryzae MTCC 262 & Deproteinized whey & 3 & 11.9 & [38] \\
\hline Rhizopus oryzae NRRL 395 & Steamed rice & 3 & $20^{\mathrm{b}}$ & [45] \\
\hline Rhizopus oryzae 0602 & Glucose, peptone, yeast extract, etc. & 4 & 4.91 & [46] \\
\hline Rhizopus oryzae 0263 & Glucose, peptone, yeast extract, etc. & 4 & 4.43 & {$[46]$} \\
\hline Cunninghamella echinulata & Glucose, peptone, yeast extract, etc. & 4 & 7.14 & {$[46]$} \\
\hline Aspergillus niger TISTR3245 & PDB & 16 & 11 & [47] \\
\hline Rhizopus oryzae TISTR3189 & PDB & 6 & 14 & [47] \\
\hline Zygosaccharomyces rouxii TISTR5058 & PDB & 2 & 3.6 & [47] \\
\hline Candida albicans TISTR5239 & PDB & 2 & 4.4 & [47] \\
\hline Rhizopus oryzae YPF-61A & Glucose & 6 & 7.5 & [48] \\
\hline Rhizopus oryzae NRRL 395 & $100 \%$ potato hydrolysate & 3 & 25 & [34] \\
\hline Rhizopus oryzae ATCC 20344 & $50 \%$ manure liquid with $20 \mathrm{~g} / \mathrm{L}$ glucose & 2 & 21 & [33] \\
\hline
\end{tabular}

a Data shown are glucosamine content

b Data shown is chitin/chitosan content only in mycelia

\section{Table 5 Energy balance of the self-sustaining biorefinery}

\begin{tabular}{lll}
\hline Energy balance $^{\mathbf{a}}$ & AD & EC process $^{\text {Fungal fermentation }^{\mathbf{b}}}$ \\
\hline Energy input (MJ/kg dry feedstock) & $-0.16^{\mathrm{c}}$ & $-1.47^{\mathrm{d}}$ \\
Energy output (MJ/kg dry feedstock) & $6.95^{\mathrm{f}}$ & 0 \\
Net energy (MJ/kg dry feedstock) & 6.79 & -1.47 \\
Overall net energy (MJ/kg dry feedstock) & 1.69 & -3.63
\end{tabular}

All inputs are negative, and all outputs are positive

a Data were calculated and adjusted based on $1 \mathrm{~kg}$ dry animal wastes

b The fungal fermentation includes unit operations of pretreatment, enzymatic hydrolysis and fungal fermentation

c The energy input for the AD unit includes both heat and electricity

d The energy input for the EC unit is $446.65 \mathrm{~kJ} / \mathrm{L}$ liquid digestate

e The energy input for pretreatment, enzymatic hydrolysis, fungal fermentation and post-processing is $1.25 \mathrm{MJ} / \mathrm{L}$ fermentation broth (unpublished data)

$f$ The energy output of the AD is the methane energy. Low heating value of methane of $50 \mathrm{~kJ} / \mathrm{g}$ methane was used for the calculation

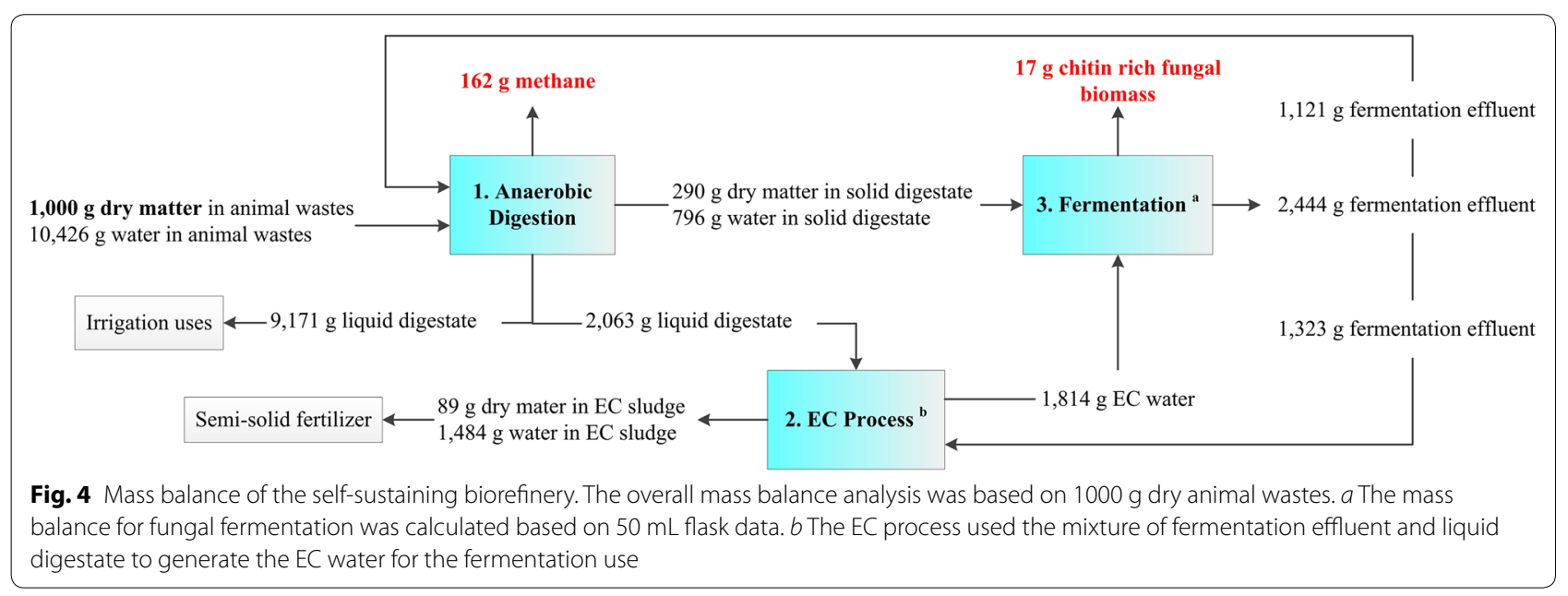


animal wastes, respectively. Correspondingly, the selfsustaining concept that synergistically integrates $\mathrm{AD}$, $\mathrm{EC}$, and fungal fermentation to convert agricultural wastes into value-added product is concluded. The concept provides a win-win solution for agricultural waste management and biorefining of value-added chemical production.

\section{Additional file}

Additional file 1. Additional figure and tables. Additional information is available at Biotechnology for Biofuels journal's website.

\section{Abbreviations}

AD: anaerobic digestion; HRT: hydraulic retention time; EC: electrocoagulation; COD: chemical oxygen demand; TS: total solids; VS: volatile solids; TP: total phosphorus; TN: total nitrogen.

\section{Authors' contributions}

$\mathrm{ZL}, \mathrm{WL}$, and $\mathrm{YL}$ conceived and designed the study, analyzed and interpreted data, and wrote the manuscript. ZL conducted experiments. All authors read and approved the final manuscript.

\section{Acknowledgements}

The authors would like to thank Mr. Andrew Austin at Scenic View Dairy for his technical support and the AgBioResearch at Michigan State University for funding this work through faculty salaries.

\section{Competing interests}

The authors declare they have no competing interests.

\section{Availability of supporting data}

Data will be made available upon request.

\section{Consent for publication}

All authors approved the manuscript.

\section{Funding}

This study is funded by the AgBioResearch at Michigan State University.

Received: 22 April 2016 Accepted: 31 August 2016

Published online: 17 September 2016

\section{References}

1. USDA National Agricultural Statistics Service: farms, land in farms, and livestock operations; 2009

2. Golan E. The US food waste challenge. Washington, D.C.: Department of Agriculture; 2013.

3. NallathambiGunaseelan V. Anaerobic digestion of biomass for methane production: a review. Biomass Bioenerg. 1997;13(1-2):83-114.

4. Liu Z, Ruan Z, Xiao Y, Yi Y, Tang YJ, Liao W, Liu Y. Integration of sewage sludge digestion with advanced biofuel synthesis. Bioresour Technol. 2013;132:166-70

5. Teater C, Yue Z, MacLellan J, Liu Y, Liao W. Assessing solid digestate from anaerobic digestion as feedstock for ethanol production. Bioresour Technol. 2011;102(2):1856-62.

6. Yue ZB, Teater C, Liu Y, MacLellan J, Liao W. A sustainable pathway of cellulosic ethanol production integrating anaerobic digestion with biorefining. Biotechnol Bioeng. 2010;105(6):1031-9.

7. Liao W, Liu Y, Hodge D. Integrated farm-based biorefinery. In: Qureshi N, Hodge D, Vertes A, editors. Biorefineries: Integrated Biochemical Processes for Liquid Biofuels. New York: Elsevier; 2014. p. 255-70.
8. Liu Z, Stromberg D, Liu X, Liao W, Liu Y. A new multiple-stage electrocoagulation process on anaerobic digestion effluent to simultaneously reclaim water and clean up biogas. J Hazard Mater. 2015;285:483-90.

9. Rodriguez J, Castrillon L, Maranon E, Sastre H, Fernandez E. Removal of non-biodegradable organic matter from landfill leachates by adsorption. Water Res. 2004;38(14-15):3297-303.

10. Tyagi VK, Khan AA, Kazmi AA, Chopra AK. Enhancement of coagulation flocculation process using anionic polymer for the post treatment of UASB reactor effluent. Sep Sci Technol. 2010;45(5):626-34.

11. Apollo S, Onyango MS, Ochieng A. An integrated anaerobic digestion and UV photocatalytic treatment of distillery wastewater. J Hazard Mater. 2013;261:435-42

12. Battimelli A, Millet C, Delgenes JP, Moletta R. Anaerobic digestion of waste activated sludge combined with ozone post-treatment and recycling. Water Sci Technol. 2003;48(4):61-8.

13. Liu Z, Stromberg D, Liu X, Liao W, Liu Y. A new multiple-stage electrocoagulation process on anaerobic digestion effluent to simultaneously reclaim water and clean up biogas. J Hazard Mater. 2014;285C:483-90.

14. Mollah MY, Schennach R, Parga JR, Cocke DL. Electrocoagulation (EC)-science and applications. J Hazard Mater. 2001;84(1):29-41.

15. Sanyal O, Liu Z, Meharg BM, Liao W, Lee I. Development of polyelectrolyte multilayer membranes to reduce the COD level of electrocoagulation treated high-strength wastewater. J Membr Sci. 2015;496:259-66.

16. Evangelisti S, Lettieri P, Borello D, Clift R. Life cycle assessment of energy from waste via anaerobic digestion: a UK case study. Waste Manag. 2014;34(1):226-37.

17. Torres-Climent A, Martin-Mata J, Marhuenda-Egea F, Moral R, Barber X, Perez-Murcia MD, Paredes C. Composting of the solid phase of digestate from biogas production: optimization of the moisture, C/N ratio, and ph conditions. Commun Soil Sci Plant Anal. 2015;46:197-207.

18. Sun L, Wan S, Luo W. Biochars prepared from anaerobic digestion residue, palm bark, and eucalyptus for adsorption of cationic methylene blue dye: characterization, equilibrium, and kinetic studies. Bioresour Technol. 2013;140:406-13.

19. Yue Z, Teater C, MacLellan J, Liu Y, Liao W. Development of a new bioethanol feedstock - anaerobically digested fiber from confined dairy operations using different digestion configurations. Biomass Bioenerg. 2011;35(5):1946-53

20. Zhong Y, Ruan ZH, Zhong YK, Archer S, Liu Y, Liao W. A self-sustaining advanced lignocellulosic biofuel production by integration of anaerobic digestion and aerobic fungal fermentation. Bioresour Technol. 2015:179:173-9.

21. Yusof NLBM, Lim LY, Khor E. Preparation and characterization of chitin beads as a wound dressing precursor. J Biomed Mater Res. 2001;54(1):59-68.

22. Ravi Kumar MNV. A review of chitin and chitosan applications. React Func Polym. 2000;46(1):1-27

23. Wu T, Zivanovic S, Draughon FA, Conway WS, Sams CE. Physicochemical properties and bioactivity of fungal chitin and chitosan. J Agric Food Chem. 2005;53(10):3888-94

24. Teng WL, Khor E, Tan TK, Lim LY, Tan SC. Concurrent production of chitin from shrimp shells and fungi. Carbohydr Res. 2001;332(3):305-16.

25. Hermosa R, Viterbo A, Chet I, Monte E. Plant-beneficial effects of Trichoderma and of its genes. Microbiology. 2012;158(1):17-25.

26. Nutrition SoDC, Nutrition CoA, Council NR. Nutrient requirements of dairy cattle. 7th Revised ed. The National Academies Press: Washington, D.C; 2001.

27. Liu Z, Liu Y. Synergistic integration of electrocoagulation and algal cultivation to treat liquid anaerobic digestion effluent and accumulate algal biomass. Process Biochem. 2016;51(1):89-94.

28. Ruan Z, Zanotti M, Wang X, Ducey C, Liu Y. Evaluation of lipid accumulation from lignocellulosic sugars by Mortierella isabellina for biodiesel production. Bioresour Technol. 2012;110:198-205.

29. Sluiter A, Ruiz R, Scarlata C, Sluiter J, Templeton D. Determination of extractives in biomass. In: NREL Laboratory Analytical Procedures for Standard Biomass Analysis. 2005. http://www.nrel.gov/docs/gen/ fy08/42619.pdf. Accessed Jan 2014.

30. Peniston QP, Johnson EL. Method of recovering chitosan and other by-products from shellfish waste and the like. Washington, D.C.: Google Patents; 1975. 
31. Dhillon GS, Kaur S, Brar SK, Verma M. Green synthesis approach: extraction of chitosan from fungus mycelia. Crit Rev Biotechnol. 2013;33(4):379-403.

32. Chysirichote T, Reiji T, Asami K, Ohtaguchi K. Quantification of the glucosamine content in the filamentous fungus Monascus ruber cultured on solid surfaces. J Basic Microbiol. 2014;54(5):350-7.

33. Liao W, Liu Y, Frear C, Chen S. Co-production of fumaric acid and chitin from a nitrogen-rich lignocellulosic material—dairy manure—using a pelletized filamentous fungus Rhizopus oryzae ATCC 20344. Bioresour Technol. 2008;99(13):5859-66.

34. Liu Y, Liao W, Chen S. Co-production of lactic acid and chitin using a pelletized filamentous fungus Rhizopus oryzae cultured on cull potatoes and glucose. J Appl Microbiol. 2008;105(5):1521-8.

35. Arcidiacono S, Kaplan DL. Molecular weight distribution of chitosan isolated from Mucor rouxii under different culture and processing conditions. Biotechnol Bioeng. 1992;39(3):281-6.

36. Mollah MY, Morkovsky P, Gomes JA, Kesmez M, Parga J, Cocke DL. Fundamentals, present and future perspectives of electrocoagulation. J Hazard Mater. 2004;114(1-3):199-210.

37. Saito K, Hasa Y, Abe H. Production of lactic acid from xylose and wheat straw by Rhizopus oryzae. J Biosci Bioeng. 2012;114(2):166-9.

38. Chatterjee S, Chatterjee S, Chatterjee BP, Guha AK. Enhancement of growth and chitosan production by Rhizopus oryzae in whey medium by plant growth hormones. Int J Biol Macromol. 2008;42(2):120-6.

39. Wu M, Mintz M, Wang M, Arora S. Consumptive water use in the production of bioethanol and petroleum gasoline. Chicago: Center for Transportation Research, Energy Systems Division, Argonne National Laboratory; 2008.
40. Subhadra BG, Edwards M. Coproduct market analysis and water footprint of simulated commercial algal biorefineries. Appl Energy. 2011;88(10):3515-23

41. Fingerman KR, Torn MS, O'Hare MH, Kammen DM. Accounting for the water impacts of ethanol production. Environ Res Lett. 2010;5(1):014020.

42. Martín M, Ahmetovic E, Grossmann IE. Optimization of water consumption in second generation bioethanol plants. Ind Eng Chem Res. 2010;50(7):3705-21.

43. Queiroz MI, Hornes MO, da Silva Manetti AG, Zepka LQ, Jacob-Lopes E. Fish processing wastewater as a platform of the microalgal biorefineries. Biosyst Eng. 2013;115(2):195-202.

44. Fava F, Totaro G, Diels L, Reis M, Duarte J, Carioca OB, Poggi-Varaldo HM, Ferreira BS. Biowaste biorefinery in Europe: opportunities and research and development needs. New Biotechnol. 2015;32(1):100-8.

45. Hang YD. Chitosan production from Rhizopus oryzae mycelia. Biotechnol Lett. 1990;12(12):911-2.

46. Tan SC, Tan TK, Wong SM, Khor E. The chitosan yield of zygomycetes at their optimum harvesting time. Carbohydr Polym. 1996;30(4):239-42.

47. Pochanavanich P, SuntornsukW. Fungal chitosan production and its characterization. Lett Appl Microbiol. 2002;35(1):17-21.

48. Yoshihara K, Shinohara Y, Hirotsu T, Izumori K. Chitosan productivity enhancement in Rhizopus oryzae YPF-61 A by D-psicose. J Biosci Bioeng 2003;95(3):293-7.

\section{Submit your next manuscript to BioMed Central and we will help you at every step:}

- We accept pre-submission inquiries

- Our selector tool helps you to find the most relevant journal

- We provide round the clock customer support

- Convenient online submission

- Thorough peer review

- Inclusion in PubMed and all major indexing services

- Maximum visibility for your research

Submit your manuscript at www.biomedcentral.com/submit
() Biomed Central 